Chapter Title: Quality Assurance and Enhancement: Policy and Practice

Chapter Author(s): Rachel Mulvey and Roberta Piazza

Book Title: European Competence Standards for the Academic Training of Career Practitioners

Book Subtitle: NICE Handbook Volume 2

Book Editor(s): Christiane Schiersmann, Sif Einarsdóttir, Johannes Katsarov, Jukka

Lerkkanen, Rachel Mulvey, Jacques Pouyaud, Kestutis Pukelis, Peter Weber

Published by: Verlag Barbara Budrich. (2016)

Stable URL: https://www.jstor.org/stable/j.ctvd7w8vf.10

JSTOR is a not-for-profit service that helps scholars, researchers, and students discover, use, and build upon a wide range of content in a trusted digital archive. We use information technology and tools to increase productivity and facilitate new forms of scholarship. For more information about JSTOR, please contact support@jstor.org.

Your use of the JSTOR archive indicates your acceptance of the Terms \& Conditions of Use, available at https://about.jstor.org/terms

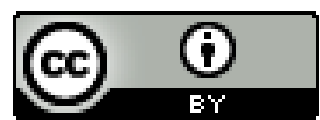

This book is licensed under a Creative Commons Attribution 4.0 International License (CC BY 4.0). To view a copy of this license, visit

https://creativecommons.org/licenses/by/4.0/.

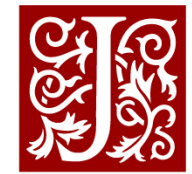

Verlag Barbara Budrich is collaborating with JSTOR to digitize, preserve and extend access to European Competence Standards for the Academic Training of Career Practitioners 


\section{QUALITY ASSURANCE AND}

\section{Enhancement: Policy and Practice}

by Rachel Mulvey and Roberta Piazza 
The partners of the NICE network have worked collaboratively to articulate European Competence Standards in this handbook as well as common points of reference (NICE 2012). This demonstrates a shared understanding that quality benchmarks are considered to be essential for the effective training of career practitioners. Notwithstanding this intrinsic motivation, the changing external operating environment for higher education providers across Europe makes increasing demands from the quality perspective. The Bologna Declaration (1999) is pre-eminent here alongside the more commercial aspect of universities needing to demonstrate value for money to governments and students alike.

This chapter considers how programme leaders (at university level) can first assure the quality of their courses from the outset (quality assurance), and then engage in a process of continuous quality enhancement for as long as the programme is offered. The chapter identifies sources of relevant European policies along with sources of support and guidance to colleagues in the community of practice who are working through quality processes. It argues that engaging with quality assurance and enhancement (QAE) can take many forms; it can be a formal process or an informal action, an evaluative reporting process or an individual act of reflection by a career practitioner involved in training. A checklist offers an overview of what is typically included in formal evaluation of a degree programme.

The chapter goes on to discuss how the competence standards and common points of reference from NICE can be used for quality assurance and enhancement of academic training. For demonstration, NICE partners share their experience of using the competence standards and common points of reference in QAE. These illustrations are adapted from items previously published in NICE newsletters between 2013 and 2015. 


\subsection{Policy Drivers}

For many decades, the European Union regarded education as a state-level concern, until the creation of the European Higher Education Area (EHEA) was seen as a key way of promoting the mobility and employability of all EU citizens. The Sorbonne Declaration (1998) therefore proposed that the segmentation of the higher education sector in Europe was outdated and harmful. It stressed the importance of education and educational cooperation in the development and strengthening of stable, peaceful and democratic societies and aimed to harmonise the architecture of the European Higher Education Area.

The Bologna Declaration (1999), along with the subsequent Bologna Process, consisted of a voluntary commitment of each signatory country to reform its own education system. The over-arching intention was to create "a more complete and far-reaching Europe" through "strengthening its cultural, social, scientific and technological dimensions". Far-reaching here could be understood as a reference to the increased geographical spread of the EU. The specific focus was to increase the competitiveness of the EHEA. It is important to note that this reform was not imposed on the national governments or universities. The legal was the Maastricht Treaty, which clearly permitted joint action in the field of education "while fully respecting the responsibility of the Member States for the content of teaching and the organisation of education systems and cultural and linguistic diversity" (Maastricht Treaty 1992, Article 126).

The Bologna Process has been an important driver of change and reform in European higher education, working towards a EHEA, where qualifications issued in one European country will we recognised in other European countries. A couple of major achievements are:

- The Framework for Qualifications for the European Higher Education Area (Bergen 2005, Appendix 1), through which the three academic cycles (Bachelor, Master and Doctorate) are becoming standardised across Europe ${ }^{1}$, and

- The European Credit Transfer and Accumulation System (ECTS), promoting studentcentred learning based on clearly articulated learning outcomes (ECTS Users' Guide 2015).

Quality assurance has gained a prominent role in the Bologna Process. In 2003, the ministers responsible for higher education recognised that the "quality of higher education has proven to be at the heart of the setting up of a European Higher Education Area" (Berlin 2003, p. 3). They also stressed that "the primary responsibility for quality assurance in higher education lies with each institution itself and this provides the basis for real accountability of the academic system within the national quality framework" (ibid.).

1 The three academic cycles are endorsed in the European Qualifications Framework for Lifelong Learning (EQF 2008). 
This respect for university autonomy has been retained and is still evident in current reports (e.g. European Commission et al. 2015). As the last Report on Progress in Quality Assurance in Higher Education highlights, higher education institutions "have the ultimate responsibility for the quality of their offering (setting, monitoring and renewing their quality goals through ,internal' quality assurance)" (European Commission 2014, p. 3). However, as the report goes on, they are nowadays supported by external quality assurance agencies (QAAs), which assess quality standards, evaluate institutions, accredit programmes or benchmark the performance of higher education institutions against each other (ibid.). Public authorities are seen to have a duty "to ensure that the quality of individual institutions, and of their higher education system as a whole, are fit for purpose" (ibid.). Where national QAAs offer reference points, higher education providers have a shared starting point to set, describe and assure the quality and academic standards of their degree programmes. For example, the British QAA reports on the higher education institutions they assess, outlining how the QAA's criteria are met and what recommendations for improvement have been made. Additionally, the QAA offers examples of good practice.

By quality assuring the programme of study offered, the programme leader concerned is able to ensure that academic standards, academic quality and any relevant information about their higher education provision are all comparable to other higher education institutions nationally and within Europe. In addition, effective quality assurance activities, ensuring that programmes are well-designed, monitored and periodically reviewed, help to establish and maintain the confidence of students and other stakeholders in higher education institutions. This enables students and graduates greater mobility within Europe, and helps higher education providers to ensure that graduates have the right skills for the labour market and to reduce skills mismatches.

At the European level, the European Quality Assurance Register for Higher Education (EQAR) has been established to help harmonise quality assurance across Europe. National QAAs, which are registered with EQAR, shall be able to perform their activities across the European Higher Education Area, i.e. in 47 countries, while complying with national requirements (Bucharest 2012, p. 2). The existence of an institution like EQAR is particularly important for the quality assurance of joint degree programmes of higher educations from different countries, and for the coordination of quality assurance systems across Europe. Furthermore, common Standards and Guidelines for Quality Assurance in the European Higher Education Area shall contribute to the "common understanding of quality assurance for learning and teaching across borders among all stakeholders" (ESG 2015, p. 4). Many activities like these are going on at the European level, which shall help to build mutual trust and better recognition of qualifications and programmes between countries in the future. Appendix 2 presents an overview of relevant resources.

Table 3 presents an overview of important questions for the quality assurance and enhancement of degree programmes in the form of a checklist. The exact requirements for the vali- 
dation of new programmes and the enhancement of existing programmes will vary from one university to another, because each university has autonomy in its power to award degrees. Nevertheless, because of the harmonisation through the Bologna Process (1999), it is likely that most universities will consider similar issues when assuring quality. In relation to the approval, monitoring and periodic review of programmes and awards, the ENQA (2009) defines some guidelines to assure the quality of programmes.

\section{Checklist: Quality Assurance and Enhancement of Degree Programmes}

\section{Validity of the Assurance Process}

$\checkmark \quad$ Are there formal programme approval procedures by a body other than that teaching the programme? For example, does a national quality assurance agency or an accreditation body make prescriptions?

\author{
Academic Climate and Resources \\ $\checkmark \quad$ Are there enough suitably qualified staff to \\ teach the programme? \\ $\checkmark \quad$ Are there adequate resources including \\ books, computers, teaching rooms? \\ $\checkmark \quad$ Are appropriate learning resources \\ available? \\ Learning, Teaching and Assessment Methods \\ $\checkmark \quad$ Is there a range of methods used for \\ teaching and learning? \\ $\checkmark \quad$ Are the methods of teaching and learning \\ appropriate in view of the learning \\ outcomes defined in the curriculum? \\ $\checkmark \quad$ Are individual student needs taken into \\ account in teaching? \\ $\checkmark \quad$ Is the assessment appropriate to assess the \\ published learning outcomes? \\ $\checkmark \quad$ Is there a range of assessment methods? \\ $\checkmark \quad$ Are the specific needs of different modes of \\ delivery (e.g. full time, part-time, distance \\ learning, e-learning) and types of higher \\ education (e.g. academic, vocational, \\ professional) demonstrably considered? \\ $\checkmark \quad$ Is there monitoring of the progress and \\ achievements of students?
}

Structure, Design and Curriculum Content

$\checkmark \quad$ Is the purpose and target group of the programme described in a programme profile?

$\checkmark \quad$ Are the overall aims and objectives of the programme appropriate for its purpose?

$\checkmark \quad$ Are explicit intended learning outcomes developed and published?

$\checkmark \quad$ Has careful attention been paid to curriculum design and content?

$\checkmark \quad$ Does the curriculum enable the student to meet the learning outcomes?

$\checkmark \quad$ Is the curriculum in line with similar programmes offered nationally and internationally?

$\checkmark \quad$ Are the credit points (ECTS) awarded for courses aligned to the actual workload of learners?

\section{Reviews and Quality Enhancement}

$\checkmark \quad$ Are there regular periodic reviews of programmes?

$\checkmark \quad$ Do reviews include external panel members?

$\checkmark \quad$ Are students adequately involved in quality assurance activities?

$\checkmark \quad$ Is feedback from employers, labour market representatives and other relevant organisations sought on a regular basis?

\section{Information Policy}

$\checkmark \quad$ Is up to date, impartial and objective information (both quantitative and qualitative) about the programmes and awards regularly published?

$\checkmark \quad$ Are transcripts of records offered, which allow for transnational mobility and the recognition of degrees in other countries?

Table 3: Checklist: Quality Assurance and Enhancement of Degree Programmes, all rights reserved 


\subsection{HOW NICE SUPPORTS QUALITY ASSURANCE AND ENHANCEMENT}

The European Competence Standards (ECS), the NICE Professional Roles (NPRs) and the NICE Curriculum Framework are valuable resources for the organisation and benchmarking of academic training for career practitioners. They offer common points of reference, which are external to any one university, and which represents a strong pan-European consensus based on sound research activities by experts in the field. They are of particular value in combination with the formal quality assurance and enhancement mechanisms featured above, because they add a content-related dimension.

Using the ECS and common points of reference (CPRs) can strengthen the argument for recognition of proposed degree programmes. The NICE Professional Roles are helpful in delineating what students on the proposed course are being trained to deliver in terms of their professional practice on eventual graduation. The ECS relate to these roles in defining competence standards for three types of career practitioners. They are expressed in terms of performance-oriented competences, which are assessable as a clear set of learning outcomes. The ECS are a tool that can be used by higher education institutions and teaching staff to design the curriculum (and their research and teaching activities) to help the students to acquire those competences. The ECS can therefore be considered a way to implement a strategy for the continuous quality enhancement and to increase the development of a quality culture, which recognises the importance of quality, and quality assurance, in their work. The NICE Curriculum Framework articulates resource requirements in terms of cognitive (competence-specific knowledge), affective (attitudes, values, motivations) and behavioural resources (physical and cognitive skills). Together the CPR support the development of programmes of professional training which stand up to the rigour of quality assurance for initial validation and frame continual quality enhancement for the life of the programme.

The NICE network comprises experts in the field of career education, guidance and counselling who are all peers in the European community of practice. This offers a rich opportunity for professional reflection and peer review in the process of quality assurance. Formal quality assurance processes often require the input of an external expert to confirm the level and organisation of a proposed programme is at a similar level to comparable courses elsewhere. This is reflected in the checklist on quality assurance and enhancement above (Table 3).

Beyond the expectations of a formal accreditation process, the network can enrich teaching and learning through more informal processes. This could be a simple critical reading of quality documentation, or a reality-check conversation with peers in the NICE network. A more elaborate process of this kind of peer learning, a methodology tested by a number of NICE peers across national boundaries, is presented in Chapter 7 . 
NICE partners have made use of the common points of reference (CPRs) both for informal and formal processes of quality assurance and enhancement. Relating to the checklist (Table 3), the following illustrations demonstrate how the achievements and products of NICE can be used in practice. They have been provided by NICE members, and are based on their experience in applying the CPR in the past years.

\section{Validity of the Assurance Process}

"The common points of references from NICE (2012), especially the NICE Core Competences, the NICE Curriculum Framework and the NICE Professional Roles, were used to help develop a new 60 ECTS postgraduate programme at the University of the Faroe Islands. The NICE Curriculum Framework provided an important common benchmark and language to discuss the curriculum, in particular what to include and what to leave out. The NICE Professional Roles were used to introduce the question of professionalism to students and to explore current practices. This discussion was helpful for refining the programme and its curriculum further. Most importantly, the common points of references offer a solid foundation for the programme development and the visual presentations. The descriptions provide a good overview of issues and tools for communication and discussion with all parties."

Sif Einarsdóttir, University of Iceland

\section{Academic Climate and Resources}

"The NICE Professional Roles and the NICE Core Competences played a role in ensuring the academic climate and resources reach quality benchmarks, when guidance professors from 16 Spanish universities came together for the National Seminar of the Spanish Interuniversity Guidance Professors Network. An important conclusion of the seminar was that the NICE depiction of professional roles permits different types of guidance intervention to align, in allowing for a variation in context. The NICE Professional Roles can also be used as a benchmark against which relative strengths and weaknesses in the professional performance can be identified. This will help to project guidelines for the initial training (which must be common) and continuous formation of guidance professionals to enable their occupational performance and mobility."

Luis M. Sobrado Fernandez, University of Santiago de Compostela, Spain 


\section{Structure, Design and Curriculum Content of the Programme}

"The JAMK University of Applied Sciences in Finland has already built its career guidance and counselling education curriculum around the NICE Core Competences from 2012. It was therefore a logical step to apply the new European Competence Standards (2015) to their continuing and further education offer. Modules were selected and linked to build a relatively short course, comprising 25 credits. This course is aimed at people who working in the field, that is, offering career services - but as advisors or supporters rather than as certified career professionals. Validating a credit-rated short course means that in the future, if a person applies to JAMK for a full length career guidance and counselling education programme, their advisor-level studies will be acknowledged as having been formally accredited, which speeds up progress through the course."

Seija Koskela, Jyväskylä University of Applied Sciences (JAMK), Finland

"The Postgraduate certificate Expert in Job Placement Services, funded through the European Social Fund, opened to 18 participants, was redesigned in its second edition, using the CPRs. The competences were used to re-adapt the teaching modules, the teaching methodologies and the assessment practices. Currently, the course is the only one of its type in Italy. Many Postgraduate courses in guidance exist, but not in the specific sector of job placement. Considering the uniqueness of the course in the Italian scenario, the comparison with international guidelines to define the competences the professionals should have, has helped the course to acquire a broader perspective. The most important shift has been to change the overall aim from training an expert in job placement to a professional practitioner with more competences in career guidance activities."

Roberta Piazza, University of Catania, Italy

"The first Master level programme in Coaching Psychology in the Netherlands was validated at the Work and Organisational Psychology Department of the University of Amsterdam. Successful students demonstrate they have developed competences in line with the competence level promoted by NICE, including EQF level 6 competences of career advisors and EQF level 7 competences required from career professionals. The crosscutting areas of competence were derived from the NICE Professional Roles, specifically in the areas of career counselling, career service management, social systems interventions and generic professional functions."

Tim Theeboom, Annelies E.M. Van Vianen and Bianca Beersma, University of Amsterdam, Netherlands 


\section{Learning, Teaching and Assessment Methods}

"The NICE competence standards have been used in relation to quality assurance, not only for revisiting curriculum content, but also as a framework for reflective practice. Whilst the majority of the students at Aarhus Diploma Programme in Educational and Vocational guidance are career guidance counsellors, teachers were also very interested in the reach of the NICE competence standards, and the material included in the Common Points of Reference. The CPRs were used to frame discussions to consider whether the curriculum does translate in practice through activities such as planning, implementation and evaluation of teaching. Thus, the NICE material is helpful for the students at the Diploma Programme in order to contribute to an overall perspective on their own practice and on how the guidance tasks are organized in their own employing organisation. This dual process, of analysing both one's own practice and that of one's organisation contributes to strengthening the identity of the professionals involved, by developing aspects of the role of the career counsellor within a clear framework."

Rita Buhl and Randi Boelskifte, VIA University College, Denmark

"Formal evaluation from students on the MSc Career Coaching showed that they had found some parts of a lecture on career theory a bit confusing. Alerted to this block to learning, the programme leader was determined to try something new. Research on relevant theories of learning brought her to the presentations-by-students teaching method. Students in small groups (2-3 students) are assigned to different aspects of the course that they attend. They have to prepare a brief presentation (using PowerPoint or other material) regarding their assigned subject. They present this to their fellow students as a teaching session. In doing so, the whole group adopts the role of peer teacher. In order to do that, they have to read and compare several peer reviewed international and/or national journal articles. Then, the issues are discussed, and students exchange opinions regarding the strengths and weaknesses of each theory; and they examine their practical implications in different situations. Both student satisfaction and student performance increased, albeit on a small sample."

Julia Yates, University of East London, United Kingdom

\section{Reviews and Quality Enhancement}

"The Danube University Krems revalidated its post-graduate study programmes in career guidance and counselling, which cover: the development of career counselling; career education; career assessment \& information competences, alongside management competences and generic professional competences. The updated curricula are already based on the European 
Competence Standards of NICE. In conducting the revision of the curricula, Krems colleagues experienced the competence standards as a very helpful reference tool, which provided orientation for the developmental work of the revalidation process."

Monika Petermandl, Danube University Krems, Austria

"We used the NICE Core Competences (2012) to redesign our course contents, particularly those relating to professionalism, career education, career counselling and ethics. A team of internal and external experts undertook our review and we were delighted that Sif Einarsdóttir, our Icelandic partner, was able to join us as an external colleague. Sif made a significant contribution to the discussion and helped us to demonstrate that we are promoting 'internationalisation' and 'innovation in teaching and learning' by working with and supporting our students."

Graham Allan and Janet Moffett, University of the West of Scotland, United Kingdom

"In the last couple of years, as a direct result of the Bologna Process, there has been universitywide activity around harmonising our existing quality processes including a taskforce, which collects and analyses data on student achievement, which in turn informs quality enhancement. We've re-organised and standardised the module handbooks and have used the NICE descriptors as a kind of benchmark in this process. We have seen this as a chance to reflect, and to sharpen our focus. The NICE Professional Roles have helped to frame student destinations and to reflect greater sensitivity around the different professional roles our students will be taking up once qualified. It has helped us ensure that our study programme prepares students for their professional practice."

Peter Weber, University of Heidelberg, Germany 